\title{
Multiple non-cell-autonomous defects underlie neocortical callosal dysgenesis in $\mathbf{N}$ fib-deficient mice Michael Piper ${ }^{1}$, Randal X Moldrich1 ${ }^{1}$ Charlotta Lindwall1,2, Erica Little ${ }^{1}$, Guy Barry1, Sharon Mason ${ }^{1}$, Nana Sunn1, Nyoman Dana Kurniawan², Richard M Gronostajski ${ }^{4}$ and Linda J Richards*1,5,6
}

Address: ${ }^{1}$ Queensland Brain Institute, The University of Queensland, Brisbane, Queensland, Australia, ${ }^{2}$ Institute for Neuroscience and Physiology, Sahlgrenska Academy, University of Gothenburg, Sweden, ${ }^{3}$ Centre for Magnetic Resonance, The University of Queensland, Brisbane, Queensland, Australia, ${ }^{4}$ Department of Biochemistry and the Program in Neuroscience, State University of New York at Buffalo, Buffalo, NY, USA, ${ }^{5}$ Center of Excellence in Bioinformatics and Life Sciences, Buffalo, NY, USA and ${ }^{6}$ The School of Biomedical Sciences, The University of Queensland, Brisbane, Queensland, Australia

Email: Michael Piper - m.piper@uq.edu.au; Randal X Moldrich -r.moldrich@uq.edu.au; Charlotta Lindwall - charlotta.lindwall@neuro.gu.se; Erica Little - e.little@uq.edu.au; Guy Barry - g.barry@uq.edu.au; Sharon Mason -s.mason1@uq.edu.au; Nana Sunn - n.sunn@uq.edu.au; Nyoman Dana Kurniawan -n.kurniawan@uq.edu.au; Richard M Gronostajski - gronos@mac.com; Linda J Richards* - richards@uq.edu.au

* Corresponding author

Published: 4 December 2009

Neural Development 2009, 4:43 doi:10.1186/1749-8104-4-43
Received: 5 August 2009

Accepted: 4 December 2009

This article is available from: http://www.neuraldevelopment.com/content/4/I/43

(c) 2009 Piper et al; licensee BioMed Central Ltd.

This is an Open Access article distributed under the terms of the Creative Commons Attribution License (http://creativecommons.org/licenses/by/2.0), which permits unrestricted use, distribution, and reproduction in any medium, provided the original work is properly cited.

\begin{abstract}
Background: Agenesis of the corpus callosum is associated with many human developmental syndromes. Key mechanisms regulating callosal formation include the guidance of axons arising from pioneering neurons in the cingulate cortex and the development of cortical midline glial populations, but their molecular regulation remains poorly characterised. Recent data have shown that mice lacking the transcription factor Nfib exhibit callosal agenesis, yet neocortical callosal neurons express only low levels of $\mathrm{Nfib}$. Therefore, we investigate here how $\mathrm{Nfib}$ functions to regulate non-cell-autonomous mechanisms of callosal formation.
\end{abstract}

Results: Our investigations confirmed a reduction in glial cells at the midline in $\mathrm{Nfib}^{-/}$mice. To determine how this occurs, we examined radial progenitors at the cortical midline and found that they were specified correctly in Nfib mutant mice, but did not differentiate into mature glia. Cellular proliferation and apoptosis occurred normally at the midline of $N$ fib mutant mice, indicating that the decrease in midline glia observed was due to deficits in differentiation rather than proliferation or apoptosis. Next we investigated the development of callosal pioneering axons in $\mathrm{Nfib}^{-/-}$mice. Using retrograde tracer labelling, we found that $N f i b$ is expressed in cingulate neurons and hence may regulate their development. In $\mathrm{Nfib}^{-/-}$mice, neuropilin I-positive axons fail to cross the midline and expression of neuropilin I is diminished. Tract tracing and immunohistochemistry further revealed that, in late gestation, a minor population of neocortical axons does cross the midline in Nfib mutants on a C57BI/6] background, forming a rudimentary corpus callosum. Finally, the development of other forebrain commissures in Nfib-deficient mice is also aberrant.

Conclusion: The formation of the corpus callosum is severely delayed in the absence of Nfib, despite Nfib not being highly expressed in neocortical callosal neurons. Our results indicate that in addition to regulating the development of midline glial populations, $\mathrm{Nfib}$ also regulates the expression of neuropilin I within the cingulate cortex. Collectively, these data indicate that defects in midline glia and cingulate cortex neurons are associated with the callosal dysgenesis seen in Nfib-deficient mice, and provide insight into how the development of these cellular populations is controlled at a molecular level. 


\section{Background}

Axonal fibre tracts enable the transfer of information between discrete parts of the brain. Within the cerebral cortex, the corpus callosum (CC), which comprises the largest fibre tract in the brain, provides connectivity between the left and right cerebral hemispheres [1,2]. The flow of information facilitated by this tract plays an integral role in many critical functions, including behaviour, emotion and higher order cognition. Indeed, defective development of this tract in humans is correlated with a large number of syndromes, such as Mowat Wilson syndrome and Aicardi syndrome, as well as disorders including autism and schizophrenia [3]. Formation of the CC requires a series of dynamic events to be co-ordinated both spatially and temporally during both embryogenesis and the postnatal period. These include correct patterning of the midline, differentiation and specification of callosal neurons within the nascent cortical plate, the development of distinct midline glial populations, targeting of axons to the contralateral hemisphere and the elimination of those supernumerary axons overproduced during development $[1,4]$. However, while the clinical significance of the CC has long been known, our understanding of the molecular determinants underlying formation of this fibre tract remains incomplete.

Research has begun to identify some of the molecular components regulating different aspects of callosal formation. For instance, the DNA-binding protein Satb2 was recently implicated as a key determinant controlling the specification of callosally projecting neurons within the cortex $[5,6]$. Furthermore, axon guidance cues, including Netrin 1 [7], class III semaphorins [8] and Slit2 [9], as well as guidance receptors such as DCC [10], neuropilin 1 (Npn1) [11], Robo1 [12] and Ryk [13] have been implicated in callosal development. In addition, the activity of callosal neurons during development is known to be required for axonal targeting and specificity through pruning within the contralateral hemisphere $[4,14]$.

Another critical determinant of CC formation is the development of distinct glial populations at the cortical midline [15]. Two midline glial populations, the glial wedge and the indusium griseum glia, are believed to regulate callosal development, in part through expression of guidance cues such as Slit2 [16,17]. Given that these glia develop relatively early compared to other cortical glial populations [18], identifying the factors regulating their development is important for understanding both glial development and axonal guidance. One gene family in particular, the Nuclear Factor One ( $N f i$ ) transcription factors, has been shown to play a central role in regulating glial development and axon tract formation during embryogenesis. Nfia was recently implicated in regulating gliogenesis in the spinal cord [19], and Nfia-deficient mice have been demonstrated to have severely reduced glial formation at the cortical midline [20]. Similarly, Nfib has been shown to regulate the formation of glia within the ammonic neuroepithelium of the developing hippocampus [21].

Mice lacking $N f i b$ have glial defects at the midline, as well as agenesis of the CC [22], but whether these defects are mechanistically related is unknown. Here we demonstrate that neither excessive apoptosis, nor aberrant proliferation at the midline, underlies the glial defect in Nfib knockout mice, but rather that radial progenitors fail to differentiate into mature glia. Furthermore, expression of Slit2 is diminished at the midline. We also report that cellautonomous defects in cingulate cortex neurons may contribute to callosal malformation in $\mathrm{fib}^{-/}$- mice. Finally, we demonstrate that, at embryonic day 18 (E18), a small population of axons does cross the midline caudally in $N f i b$-deficient mice. These results demonstrate that $N f i b$ is critical for the maturation of midline glia that are required for CC formation. Furthermore, defects in Npn1-expressing pioneering neurons may contribute to the callosal dysgenesis evident in $\mathrm{Nfib} /$ - mice, implicating multiple noncell-autonomous roles for $N f i b$ in neocortical callosal formation.

\section{Results}

\section{NFIB is expressed at the cortical midline}

Although we previously showed by retrograde labelling that NFIB was not highly expressed in neocortical callosal neurons [23], we wanted to examine what other cells expressed NFIB at the midline. Immunohistochemistry on $6 \mu \mathrm{m}$ coronal paraffin sections from E18 wildtype brains (Figure 1A) demonstrated the expression of NFIB within the glial wedge and the indusium griseum, two glial populations essential for development of the CC (Figure 1B). Expression was also detected in the subcallosal sling (Figure $1 \mathrm{~B}$ ), a stream of cells originating in the subventricular zone that crosses the cortical midline ventral to the developing CC [24,25]. The Nfib knockout line was generated with a nuclear-localised lacZ reporter gene [22]. Expression of $\beta$-galactosidase at the cortical midline in E1 8 heterozygote brains was co-incident with that of NFIB (Additional file 1), enabling us to use the expression of $\beta$ galactosidase as a reliable indicator of those cells expressing NFIB. To determine if the cells in the glial wedge and indusium griseum expressing $N f i b$ were in fact glia, we double labelled E18 coronal sections with antibodies against $\beta$-galactosidase (a mouse monoclonal antibody) and glial fibrillary acidic protein (GFAP; a rabbit polyclonal antibody), a marker for mature glial cells. Many $\beta$ galactosidase-positive cells in both the glial wedge and the indusium griseum were surrounded by GFAP-positive fibres, indicating that these glial populations are likely to express Nfib (Figure 1C, D). 


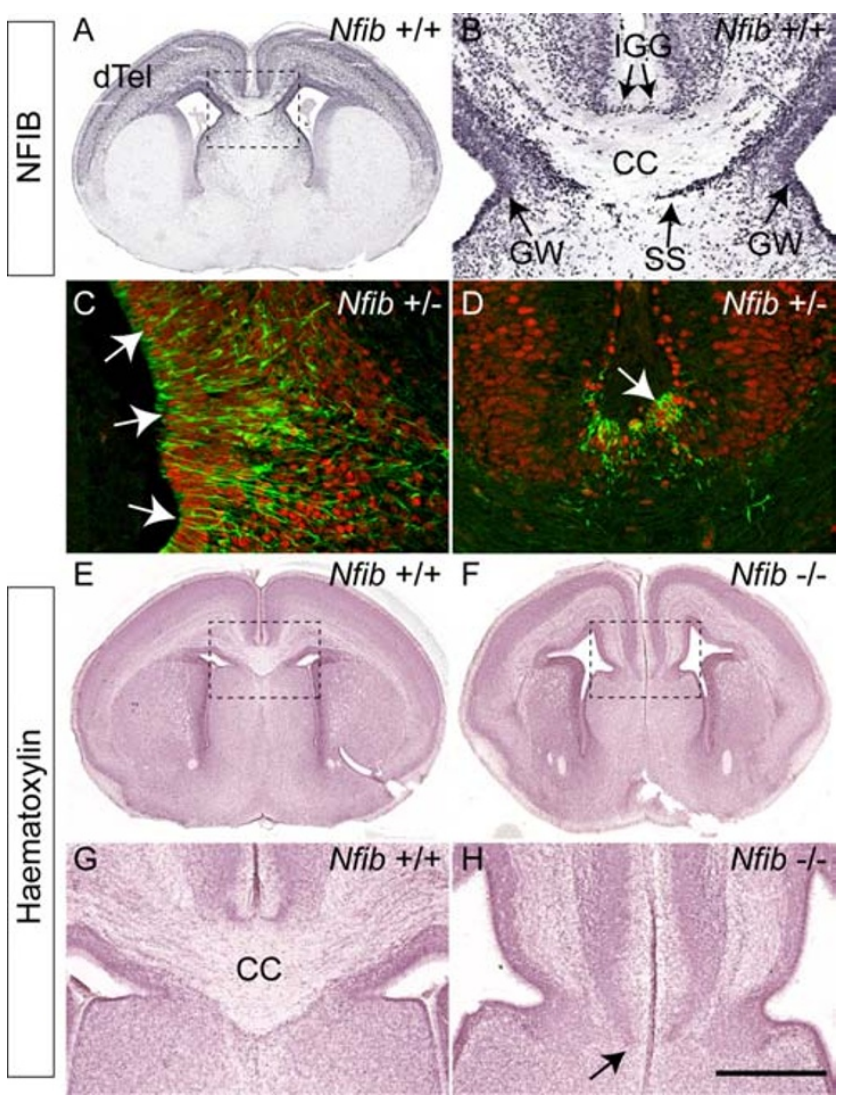

Figure I

Expression of NFIB in midline glial populations. (A, B) Coronal section of an El8 wildtype brain stained with NFIB. (A) NFIB was expressed broadly throughout the dorsal telencephalon (dTel). (B) Higher magnification view of the boxed region in $(A)$ showing NFIB expression at the cortical midline. NFIB was expressed in the glial wedge (GW), indusium griseum glia (IGG) and subcallosal sling (SS). (C, D) Confocal sections of EI $8 \mathrm{Nfib}$ heterozygote brains, demonstrating the co-expression of the $\beta$-galactosidase ( $\beta$-gal) reporter (red) and glial fibrillary acidic protein (GFAP; green) within the glial wedge $(C)$ and the indusium griseum glia (D). $\beta$-gal-positive nuclei were often surrounded by GFAP-positive fibres (arrows in C, D), indicating that GFAP-expressing glia likely express $N$ fib. (E-H) Coronal sections of wildtype $(E, G)$ and $N$ fib knockout $(\mathrm{F}, \mathrm{H})$ brains stained with haematoxylin. The corpus callosum (CC) does not form rostrally in mice lacking $\mathrm{Nfib}$ (arrow in $(\mathrm{H})$ ). Panels $(\mathrm{G})$ and $(\mathrm{H})$ are higher magnifications of the boxed regions in $(E)$ and $(F)$, respectively. Scale bars: $500 \mu \mathrm{m}$ (A, E, F); $200 \mu \mathrm{m}$ (B, G, H); $100 \mu \mathrm{m}$ (C, D).
Nfib-deficient mice exhibit a variety of cortical deficits, including absence of the basilar pons [26] and malformation of the dentate gyrus [21]. They also exhibit agenesis of the CC at E17 as determined by staining with the axonal marker L1 [22]. Haematoxylin staining of E18 wildtype and Nfib-deficient brains (Figure 1E-H) supported this finding, indicating that, in rostral sections of the mutant, formation of the CC was impaired.

\section{Glial development is curtailed at the cortical midline of Nfib-deficient mice}

The development of mature, GFAP-expressing glial populations at the cortical midline of $\mathrm{Nfib} /$ mice at E17 was reported to be reduced in the absence of this transcription factor [22]. To gain a deeper insight into glial development during callosal formation, we first conducted a timecourse of GFAP expression in Nfib-deficient and littermate control brains (Figure 2). In sections from wildtype mice, GFAP-expressing cells were first seen in the glial wedge at E15, and within the indusium griseum glia and a third midline glial population, the midline zipper glia, at E17 (Figure 2A, C, E). In the mutant, however, GFAP expression at the cortical midline was delayed until E17, when a small population of GFAP-expressing cells became evident within the glial wedge (Figure 2B, D, F). By E18, expression of GFAP within the glial wedge in the mutant had increased, but was still reduced in comparison to that seen in wildtype controls (Figure 2G, H). Moreover, at this rostro-caudal position, no GFAP expression was observed in the indusium griseum or in the midline zipper glia of the mutant mice. As the indusium griseum contains both glia and neurons [27], we also examined the expression of Tbr1, a marker of post-mitotic neurons. These data revealed that neurons were still present in the indusium griseum of mice lacking $N f i b$ (Figure 2J), from which we infer that development of this structure per se is not affected. Rather, it is specifically the development of midline glial populations that is aberrant in the Nfib mutants.

\section{Proliferation and cell death is normal at the cortical midline of Nfib null mutants}

The absence of cortical midline glial cells within Nfib-deficient mice may arise from deficiencies in cellular proliferation at the midline, excessive cellular apoptosis, or through a failure of cortical progenitors to differentiate into mature glia during embryogenesis. To determine which of these processes was responsible for the defect in glial development we observed in Nfib null mutants, we first investigated cellular proliferation at the cortical midline. We have demonstrated previously that glia within the glial wedge and indusium griseum are born predominantly between E13 and E15 [18]. We therefore analysed proliferation at the cortical midline at these ages in both wildtype and Nfib-deficient brains using the mitotic marker phosphohistone H3 (PH3; Figure 3A, B). As these 


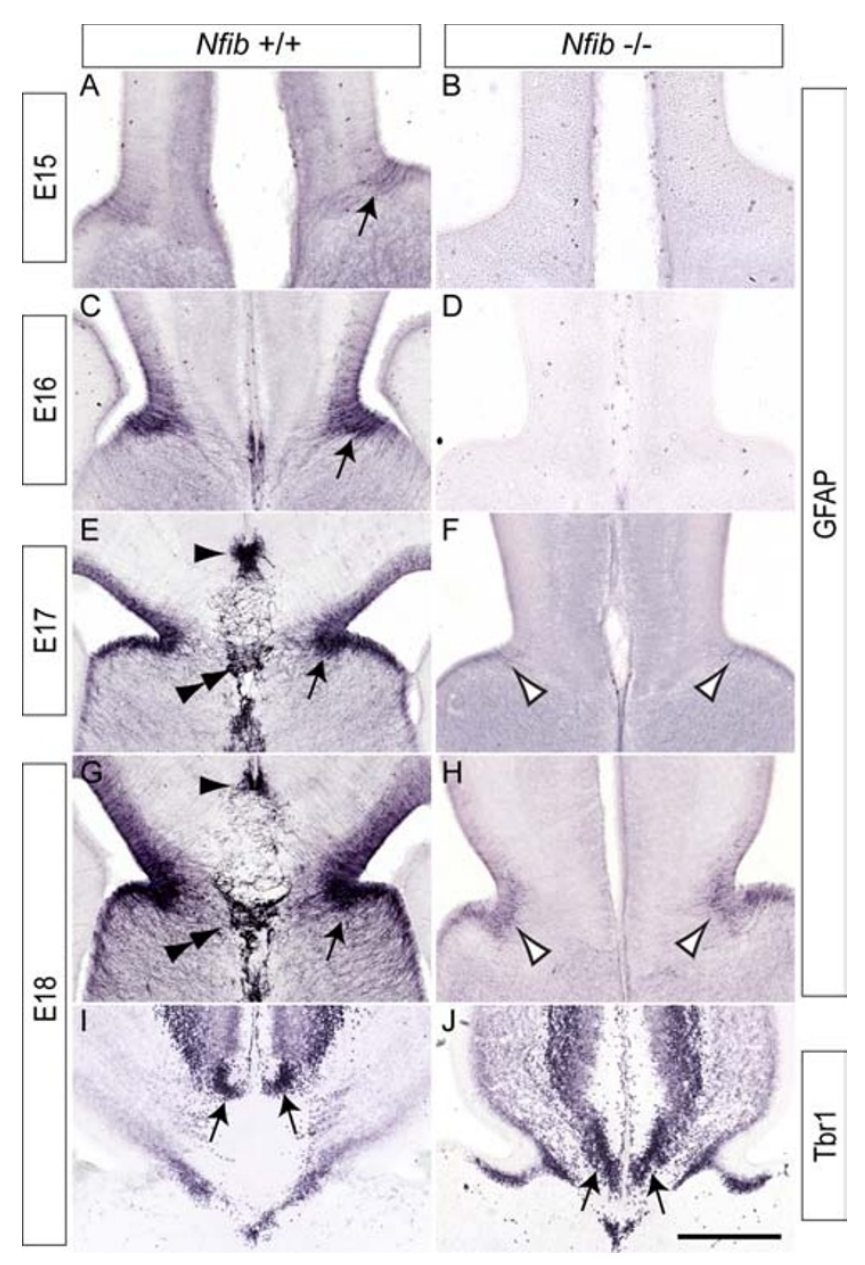

Figure 2

Reduced expression of GFAP in Nfib knockout mice. (A-H) Expression of GFAP at the cortical midline of wildtype (A, C, E, G) and Nfib-deficient (B, D, F, H) mice. In the wildtype, expression of GFAP in the glial wedge was initiated at EI5, and became progressively stronger as development proceeded (arrows in (A, C, E, G)). GFAP expression in the indusium griseum glia (arrowhead) and midline zipper glia (double arrowhead) of the wildtype was also evident from EI7 onwards (E, G). However, in the mutant, low levels of GFAP expression in the glial wedge were only observed from EI7 onwards (open arrowheads in $(F, H)$ ), whereas expression in the indusium griseum glia and midline zipper glia was absent. Neurons in the indusium griseum of the wildtype expressed Tbrl (arrows in (I)). Neurons expressing Tbrl in the indusium griseum were also observed in the mutant (arrows in (J)). Scale bars: $280 \mu \mathrm{m}$ (A, B); $250 \mu \mathrm{m}$ (C, D); 225 $\mu \mathrm{m}(\mathrm{E}, \mathrm{F}) ; 200 \mu \mathrm{m}(\mathrm{G}-\mathrm{J})$. data revealed no significant difference in the number of PH3-positive cells between Nfib mutant and wildtype sections at the cortical midline at E13, E14 or E15 (Figure 3C), we next investigated cell death using the apoptotic marker cleaved caspase 3. Very few cleaved caspase 3-positive cells were seen at the cortical midline of either wildtype or Nfib-deficient brains, and those that were found were located almost exclusively where the cerebral hemispheres fuse (arrows in Figure 3D, E). Furthermore, we observed no significant differences in apoptotic cell death at the midline between $\mathrm{Nfib}$ mutants and controls between E14 and E18 (Figure 3F). Collectively, these data indicate that neither aberrant proliferation nor excessive apoptosis are responsible for the phenotypic abnormalities observed in the absence of Nfib. We therefore next examined the specification of radial progenitor cells in $N f i b$-deficient brains, and their capacity to differentiate into mature glia.

\section{Radial progenitors are specified in the absence of $\mathbf{N f i b}$}

The intermediate filament protein nestin is expressed from E10.5 onwards in radial progenitors within the developing cortical neuroepithelium [28], and as such, nestin expression can be used to monitor the specification of radial progenitors within the cortex during embryogenesis [29]. Nestin expression at the cortical midline of Nfibdeficient mice between E14 and E18 was grossly normal when compared to that of littermate controls (Figure 4). However, analysis of nestin mRNA at E18 using quantitative real-time PCR (qPCR) on wildtype and Nfib-deficient cortical tissue showed that there were significantly higher levels of nestin in the Nfib mutant compared to wildtype controls at this age $(P<0.05, t$-test; Figure $4 \mathrm{G})$, indicative of a retention of progenitor cells in the mutant. These findings suggest that radial progenitors are specified in the absence of this transcription factor, yet are delayed in their differentiation to GFAP-positive glia in late gestation.

\section{Expression of radial glial markers at the midline is impaired}

As nestin-expressing radial progenitors differentiate into radial glia, they begin expressing astroglial markers. Two glial-specific markers used previously to investigate the differentiation of radial progenitors in the cortex are astrocyte-specific glutamate transporter (GLAST) [30] and the extracellular matrix molecule tenascin $\mathrm{C}$ [31]. To determine whether the lack of GFAP-positive midline glia in $N f i b$-deficient mice was due to a defect in the differentiation of radial progenitors, we analysed the expression of these markers during development. At E14 in wildtype mice, GLAST expression was observed in the ventricular zone of the cortex, but was higher within the region of the presumptive glial wedge (Figure 5A). This expression pattern was even more evident in the wild type at E16 (Figure 5C). However, in mutant mice, expression of GLAST was 

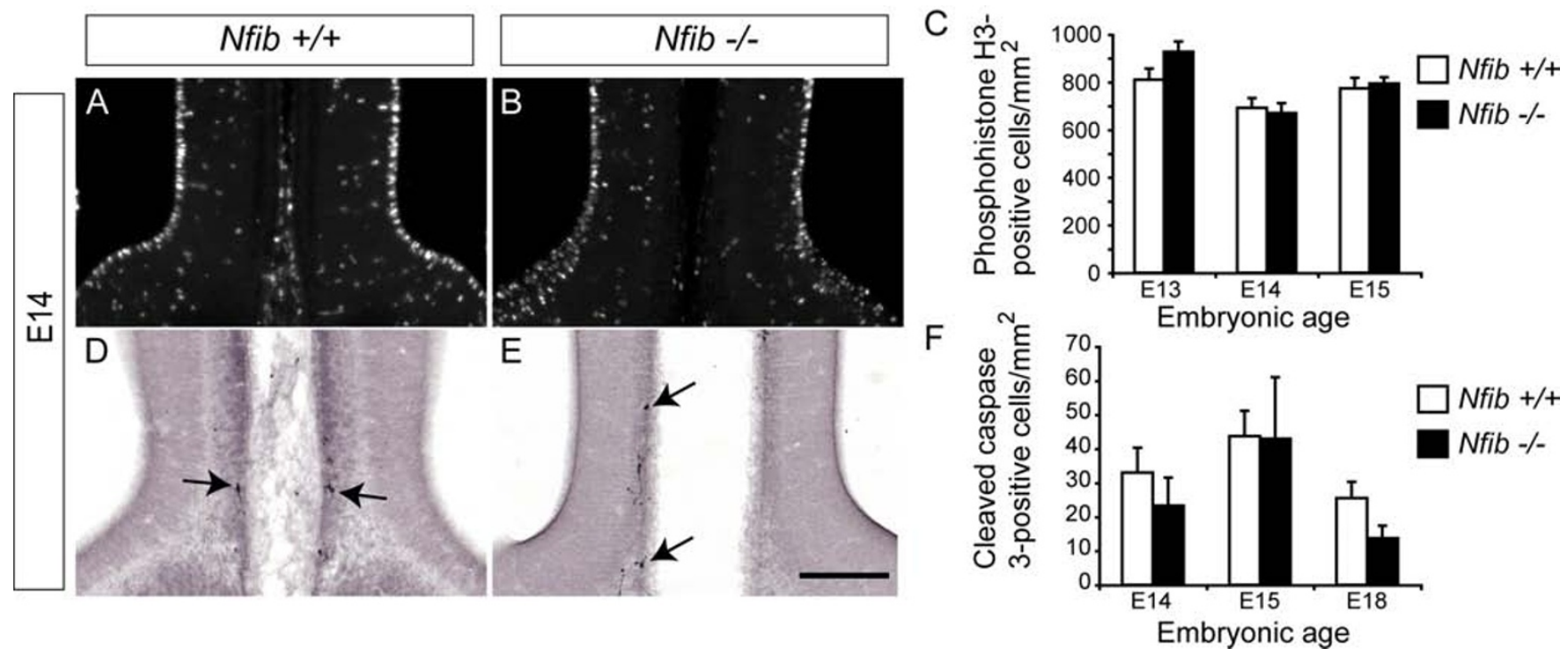

Figure 3

Normal proliferation and cell death at the cortical midline of mice lacking $\mathbf{N}$ fib. (A, B) Proliferation at the cortical midline in wildtype (A) and Nfib-deficient (B) mice was assessed with immunohistochemistry against the mitotic marker phosphohistone H3. (C) Counts of phosphohistone H3-positive cells at the cortical midline demonstrated that there was no significant difference in proliferation between Nfib null mutants and controls at EI3, EI4 or EI5. (D, E) Apoptosis at the midline in wildtype (D) and Nfib-deficient (E) brains was assessed via expression of the marker for cell death, cleaved caspase 3 . There were few apoptotic cells observed in either wildtype or knockout samples (arrows in (D, E)), and these were predominantly observed around the area where fusion between the cerebral hemispheres occurs. (F) We did not observe any significant differences in the numbers of apoptotic cells in mice lacking Nfib compared to wildtype controls at EI4, EI5 or El8. $\mathrm{n}=3$ independent replicates for both wildtype and Nfib mutants. Error bars indicate standard error of the mean. Scale bar: $300 \mu \mathrm{m}$.

clearly diminished in comparison to wildtype controls at both E14 and E16 (Figure 5B, D). At E18 in wildtype mice, GLAST expression was observed in the glial wedge, the indusium griseum glia and the midline zipper glia (Figure 5E). In mutant mice, GLAST immunoreactivity in the glial wedge was diminished, and moreover, this marker, like GFAP (Figure 2), was detected in neither the indusium griseum glia nor the midline zipper glia (Figure 5F), indicating that these mature glial populations appear absent in $N$ fib-deficient mice. Expression of tenascin $\mathrm{C}$ was also compromised in mice lacking Nfib. Comparison of wildtype and Nfib-deficient brains at E15 and E16 indicated that levels of this extracellular matrix molecule were higher in the wildtype than in the mutant (Additional file 2 ). Taken together, these data indicate that glial development is indeed impaired in Nfib knockout mice, and suggest that the lack of mature, GFAP-expressing glia at the cortical midline of the mutant results from aberrant differentiation of radial progenitors.

\section{Abnormal development of the subcallosal sling in $\mathbf{N}$ fib knockout mice}

The subcallosal sling is a population of neurons that migrate from the medial aspect of the lateral ventricles beneath the nascent CC. Migration of these neurons begins at approximately E15 and continues postnatally [24]. To determine whether formation of this structure was perturbed in mice lacking $N f i b$, we performed immunohistochemistry using two markers expressed by sling neurons, NFIA and Emx1 [24]. In wildtype mice at E18, sling neurons were observed beneath the CC (Figure 6A, C). In Nfib mutant mice, however, sling neurons were unable to cross the midline, perhaps due to the failure of the CC to form. Unlike in Nfia-deficient mice, where sling cells invade the septum [20], these cells appear to stall near the midline in the absence of $\mathrm{Nfib}$ and do not invade the septum (Figure 6B, D). This phenotype was also seen with a third marker for the subcallosal sling, calretinin (data not shown). These data suggest that correct formation of the sling requires $N f i b$ function, and further indicates that Nfia and Nfib may play different roles in relation to subcallosal sling formation.

\section{Expression of $\mathrm{Npn} \mathrm{I} \mathrm{on} \mathrm{the} \mathrm{axons} \mathrm{of} \mathrm{cingulate} \mathrm{pioneer}$ neurons is diminished in Nfib-deficient mice}

The failure of the glial wedge and the indusium griseum glia to form may underlie the callosal defects previously described for Nfib-deficient mice [22], as these glial populations have been postulated to be pivotal for the formation of this axonal tract $[16,17]$. We next investigated 


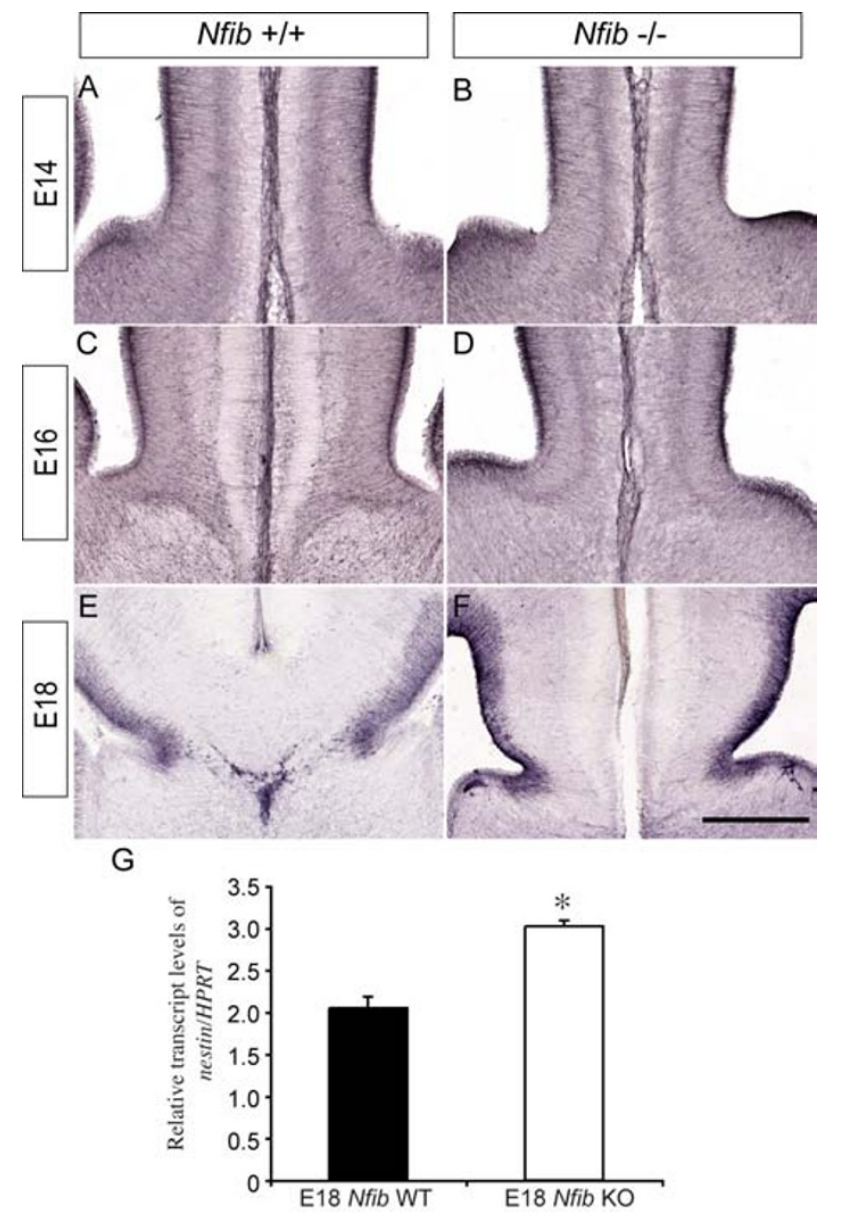

Figure 4

Radial progenitor cells express nestin at higher levels at El 8 in Nfib mutant mice. (A-F) Coronal sections of wildtype $(A, C, E)$ and $N$ fib-deficient brains $(B, D$, F) demonstrating expression of nestin. At EI4 (A, B), EI6 (C, D) and EI8 (E, F), expression of nestin in the mutant was comparable to that in the control. (G) At El8, levels of nestin mRNA were significantly higher in Nfib mutants than in littermate controls ( $* P<0.05$; $t$-test). RNA from three independent replicates for both wildtype (WT) and Nfib mutants (Nfib knockout (KO)) was analysed. Error bars indicate standard error of the mean. Scale bar: 300 $\mu \mathrm{m}$ (A, B); $250 \mu \mathrm{m}$ (C, D); $200 \mu \mathrm{m}$ (E, F).

whether defects in callosally projecting neurons could contribute to the $\mathrm{CC}$ defects observed in N $\mathrm{fib}^{-/-}$mice. Two populations of neurons extend axons that cross the midline via the $\mathrm{CC}$; neocortical callosal neurons and cingulate cortex callosal neurons [1]. The latter are thought to be critical for pioneering callosal tract formation, as neurons from the cingulate cortex are the first to extend axons across the CC $[32,33]$. Interestingly, retrograde labelling in early postnatal (P5) wildtype mice has previously shown that most callosally projecting neocortical neurons

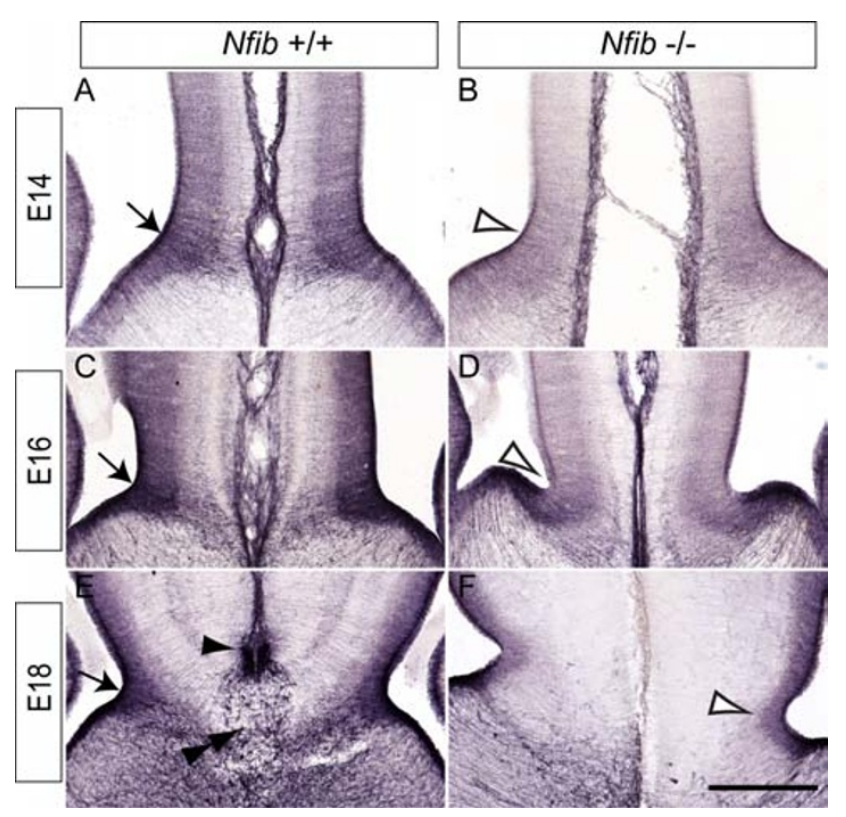

Figure 5

Diminished expression of GLAST at the cortical midline of $\mathbf{N}$ fib-deficient mice. (A-F) Expression of GLAST at EI4 (A, B), EI6 (C, D) and EI8 (E, F) in coronal sections of wildtype (A, C, E) and Nfib knockout (B, D, F) brains. At EI4 in the wildtype (A), GLAST was expressed in the glial wedge (arrow), and this expression intensified as development proceeded (arrows in (C, E)). Furthermore, GLAST expression was observed in the indusium griseum glia (arrowhead) and midline zipper glia (double arrowhead) at EI 8 in the wildtype (E). In the mutant, however, GLAST expression in the glial wedge was reduced in comparison to controls (open arrowheads; compare (B) to $(A)$, and $(D)$ to $(C)$ ). Moreover, the indusium griseum glia and midline zipper glia in the Nfib null mutant were not apparent in the mutant via GLAST immunohistochemistry at EI8 (F). Scale bars: $300 \mu \mathrm{m}$ (A, B); $250 \mu \mathrm{m}$ (C, D); $200 \mu \mathrm{m}(\mathrm{E}, \mathrm{F})$.

do not express NFIB at this age [23]. However, the broad expression pattern of NFIB in the cingulate cortex at E18 (Figure 1A) suggests that, in addition to glial deficits, cellautonomous neuronal defects within the cingulate cortex may contribute to the callosal phenotype in embryonic $N f i b$-deficient mice. To investigate this, we analysed projections arising from the cingulate cortex. Deleted in colorectal cancer (DCC) is a marker expressed selectively on callosal axons arising from neurons within the cingulate cortex [34]. In wild types at E18, DCC-expressing axons could be seen crossing the midline in the dorsal region of the CC (Figure 7A). In the mutant, DCC-expressing axons extended towards the midline (Figure $7 \mathrm{~B}$ ) but failed to cross. These data indicate that neurons within the cingulate cortex were indeed able to extend axons towards the presumptive $\mathrm{CC}$, and that this was not a growth defect. However, expression of another guidance receptor specif- 


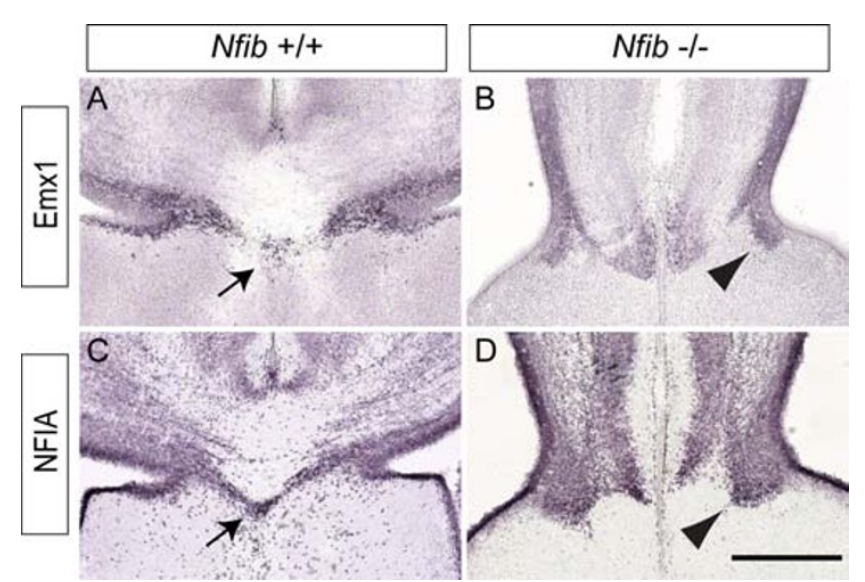

Figure 6

The subcallosal sling fails to form correctly in Nfib knockout mice. (A-D) Coronal sections of El 8 brains showing expression of $\operatorname{EmxI}(A, B)$ and NFIA (C, D). In the wildtype, cells of the subcallosal sling were seen crossing the midline immediately ventral to the CC (arrows in $(A, C)$ ). In the mutant, however, cells of the sling did not cross the midline, and instead remained ipsilateral (arrowheads in (B, D)). Scale bar: $200 \mu \mathrm{m}$.

ically localised to cingulate cortex axons, Npn1 [8], was diminished in Nfib-deficient mice in comparison to wildtype controls (Figure 7C, D). Levels of Npn1 mRNA were also significantly lower in the cortex of $N f i b$ mutants at E16, the age at which Npn1-expressing axons from cingulate pioneer neurons initiate CC formation $(P<0.05, t-$ test; Figure 7J).

We have recently postulated that Npn1-semaphorin signalling may be vital for callosal formation [8]. Thus, diminished expression of $\mathrm{Npn} 1$ on axons emanating from the cingulate cortex could also contribute to the callosal defects observed in Nfib knockout mice. To determine if NFIB was expressed in cingulate cortex neurons extending axons across the $\mathrm{CC}$, we performed tract tracing using the retrograde tracer True Blue, which was injected into the cingulate cortex of E17 embryos in utero. Embryos were then perfuse-fixed at E18. Immunohistochemistry against NFIB demonstrated that some nuclei in the cingulate cortex contralateral to the injection site were both NFIB- and True Blue-positive (Figure 7G-I), indicating that a proportion of callosally projecting cingulate neurons express $N f i b$. Interestingly, however, not all of the projections from the cingulate cortex were abnormal in the absence of $N f i b$. The perforating pathway is an ipsilateral tract extending from the cingulate cortex to the medial septum/ diagonal band of Broca and vice versa [35]. Analysis of this pathway with immunohistochemistry against the axonal marker neurofilament revealed no defect, as in both wildtype and Nfib-deficient sections, neurofilament-posi- tive axons comprising the perforating pathway intersected the callosal axons en route to their targets (Figure 7E, F).

Nfib-deficient mice exhibit callosal dysgenesis at EI8

$N f i b$-deficient mice have been reported to exhibit callosal agenesis at E17, as axons expressing the cell adhesion molecule L1 reach, but do not cross, the midline in the absence of $N f i b$ [22]. L1 is a non-specific marker for axons, and labels axons from both the cingulate cortex and neocortex. As our DCC labelling had indicated that cingulate cortex axons extend towards the cortical midline (Figure $7 \mathrm{~B})$, it remained a possibility that the L1-positive axons previously reported at the midline [22] arose not from the neocortex, but from the cingulate cortex. To investigate the origin of axons arriving at the midline, we performed tract tracing by injecting the carbocyanine dye DiI into the neocortex of both wildtype and Nfib-deficient mice at E18. Coronal sections at rostral and caudal levels in the wild type indicated that DiI-labelled axons were coursing through the $\mathrm{CC}$ and ascending into the contralateral hemisphere (Figure 8A, B, E, F). At rostral levels in the mutant, DiI-positive axons could be seen approaching, but not crossing, the cortical midline (Figure 8C, D). Furthermore, at E18 most callosally projecting neocortical axons located in layers II/III and V, identified by the expression of Satb2 [5], did not express NFIB (Additional file 3). These data indicate that, in the absence of Nfib, neocortical callosal axons are able to reach the midline, implying that callosal malformation in Nfib mutants does not arise from cell-autonomous defects within neocortical neurons. Unexpectedly, at more caudal levels, we observed a small population of axons crossing the cortical midline in the Nfib mutants (Figure 8G, H), indicating that, at this age, Nfib-deficient mice exhibit dysgenesis, not agenesis, of the CC. These findings were supported by analysis of the axonal marker GAP43, which indicated that there is indeed a population of axons that cross the midline via the CC at caudal levels in mice lacking Nfib (Figure 8I-P).

\section{Reduced expression of Slit2 at the cortical midline of $\mathbf{N f i b}$ mutants}

Mice lacking the guidance molecule Slit2 exhibit callosal defects [9], and expression of Slit2 is also reduced within the glial wedge of Nfia mutants [20]. Given the dysgenic phenotype of Nfib-deficient mice, we next examined the expression of Slit2 to determine whether the phenotype we observed could be related to altered expression of this molecule. At E18, expression of Slit2 mRNA in the wildtype was observed within the glial wedge (Figure 9A). At rostral sections in the mutant, however, Slit2 expression was markedly lower (Figure 9B), whereas at more caudal levels it was at a level more comparable to that seen in controls (Figure 9C), which could contribute to the formation of the CC caudally in the mutant. Next, we analysed expression of GFAP more caudally in Nfib-deficient 


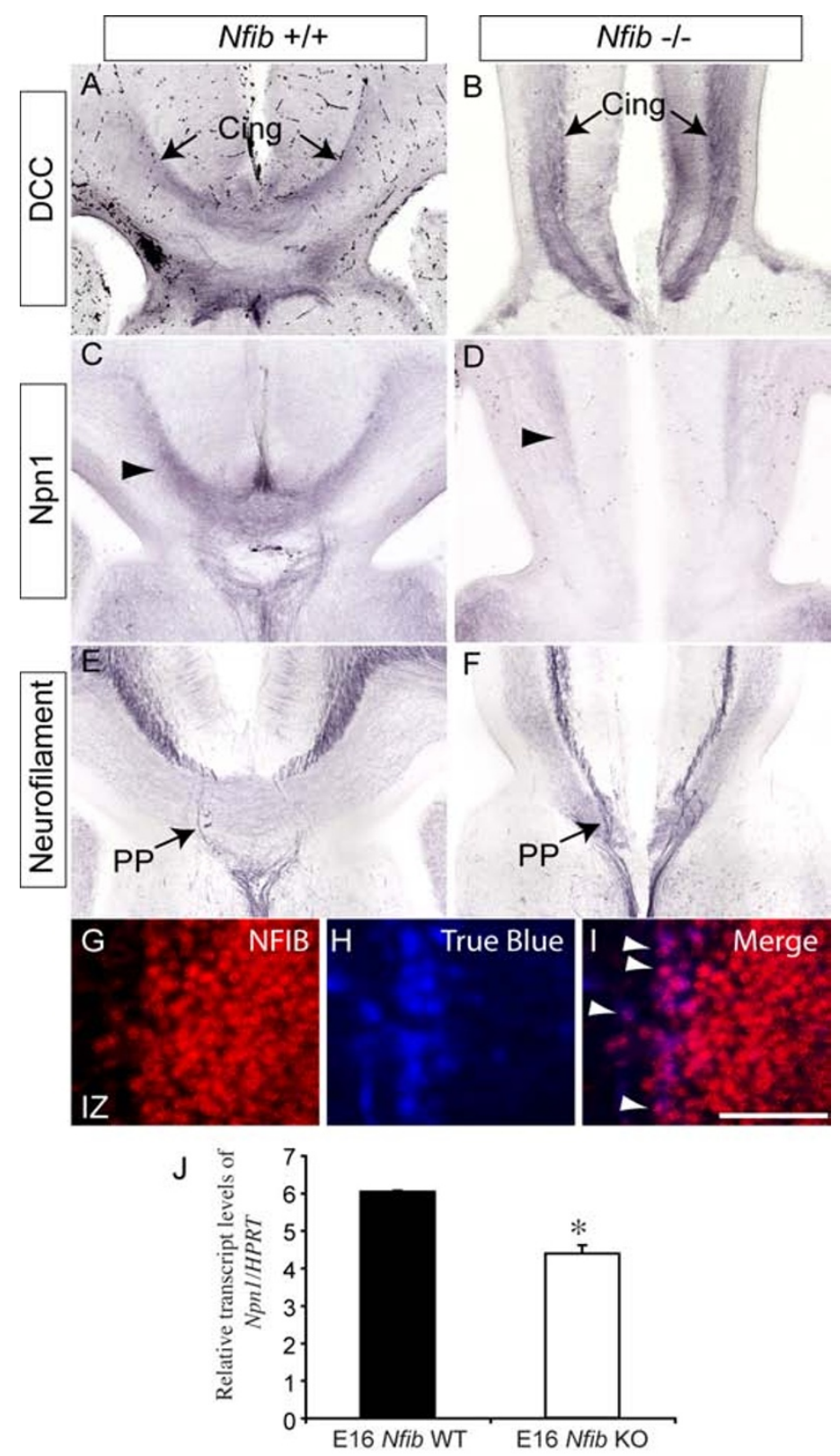

\section{Figure 7}

Expression of guidance receptors on the axons of cingulate pioneering neurons. (A-F) Expression of $D C C$ ( $A, B)$, Npn I (C, D) and neurofilament (E, F) in coronal sections of EI8 wildtype (A, C, E) and Nfib-deficient (B, D, F) brains. Axons from neurons in the cingulate cortex initiate callosal tract formation, and express the guidance receptor DCC. Expression was seen on axons from the cingulate cortex (Cing) in both the wildtype and Nfib null mutant (arrows in (A, B)). However, expression of $\mathrm{NpnI}$, another guidance receptor localised to cingulate pioneering axons, was diminished in the knockout in comparison to littermate controls (arrowheads in (C, D)). The perforating pathway (PP), shown via expression of the axonal marker neurofilament in wildtype sections (arrow in (E)), appeared relatively normal in mice lacking Nfib (arrow in (F)). (G-I) The retrograde tracer True Blue was injected into the cingulate cortex of EI7 wildtype embryos in utero. At EI8, immunohistochemistry on coronal sections against NFIB $(G)$ demonstrated that the retrograde tracer $(\mathrm{H})$ and NFIB were co-localised in a population of callosally projecting neurons in the cingulate cortex (arrowheads in (I)). (J) At El6, levels of Npn I mRNA were significantly lower in Nfib mutants than in littermate controls ( $* P<0.05$; t-test). RNA from three independent replicates for both wild type (WT) and Nfib mutants (Nfib knockout (KO)) was quantified. Error bars indicate standard error of the mean. IZ, intermediate zone. Scale bar: A-F $200 \mu \mathrm{m}$; G-I $30 \mu \mathrm{m}$. 
mice, to determine whether there were more mature glia within the region in which the callosal axons cross the midline. At rostral levels, few GFAP-positive glia were detected within the glial wedge region (Figure 9E). In more caudal regions, however, more GFAP-positive fibres were observed within the glial wedge, and GFAP-expressing cells were also found within the indusium griseum (Figure 9F). Finally, we performed co-immunofluorescent labelling of E18 $\mathrm{Nfib}^{-/}$brains with both GAP43 and GFAP. At rostral levels in the mutant, GFAP-positive glia were only observed within the glial wedge, and no axons were seen crossing the midline (Figure 9G-I). More caudally, however, labelling revealed GFAP-positive glia within both the glial wedge and indusium griseum, and callosal axons were observed crossing the midline (Figure 9J-L). Collectively, these data suggest that callosal formation in caudal regions of the Nfib mutant may be facilitated by the development, albeit delayed, of glial populations.

Defects in multiple forebrain commissures in Nfib mutants How the lack of Nfib affects the development of other forebrain commissures such as the hippocampal commissure and the anterior commissure is unknown. To address forebrain commissure development in Nfib-deficient mice, we performed diffusion tensor magnetic resonance imaging (DTMRI) to visualise the major axon tracts within the brain [36]. The axon tracts identified by DTMRI were colour-coded to denote the direction in which the fibre bundles project (blue, dorso-ventrally; red, mediolaterally; green, rostro-caudally). In a sagittal view of the midline of an E18 wildtype brain, all three major forebrain commissures (CC, hippocampal commissure and anterior commissure) were evident (Figure 10A). In the mutant, however, the anterior commissure was absent, and the CC and the hippocampal commissure, although evident, were reduced in comparison to that of the control (Figure 10B). This result was confirmed using tractography, which demonstrated a marked reduction in axon bundles within the hippocampal commissure of Nfibdeficient mice (Figure 10C, D). Furthermore, conventional analysis of these scanned brains using immunohistochemistry against GAP43 indicated the absence of the anterior commissure in the mutant (Figure 10E-H).

\section{Discussion}

The Nfi gene family is required for multiple aspects of central nervous system development [37]. Here we show that $N f i b$ regulates the differentiation of specific glial populations critical for formation of the CC, the glial wedge and the indusium griseum glia. In the absence of Nfib, the appearance of these glial populations is dramatically curtailed, although this is not due to aberrant apoptosis or proliferation. Rather, differentiation of these glia from radial progenitors at the cortical midline is impaired. Our data also indicate that expression of Npn1 on axons of pioneer neurons within the cingulate cortex of $\mathrm{Nfib}$ mutants is significantly reduced in comparison to controls. Collectively, these findings demonstrate that predominantly non-cell-autonomous defects contribute to the defects in neocortical CC formation in Nfib-deficient mice. Finally, we also show that, in late gestation, a small population of axons crosses the cortical midline at more caudal levels in Nfib mutant mice. This correlates with an increase in the levels of GFAP and Slit2, suggesting that, at least caudally, a compensatory mechanism allows both glial differentiation and CC formation in mice lacking this transcription factor.

The $N f i$ transcription factors are emerging as central players in glial lineage determination. Nfi genes have previously been shown to promote the expression of a suite of glial-specific genes in vitro, including those encoding GFAP [38], brain lipid binding protein [39], $\alpha_{1}$-antichymotrypsin [40] and tenascin C [41]. Furthermore, a number of recent studies have corroborated these findings in vivo. For instance, $N f i b$ has been shown to regulate glial differentiation within the ammonic neuroepithelium of the developing mouse hippocampus [21], while the onset of gliogenesis in the chick spinal cord requires the action of Nfia [19]. A mechanistic insight into how Nfi genes could promote gliogenesis within cortical precursors has recently been proposed [42]. Namihira and colleagues [42] demonstrated that within cortical neural progenitor cells at mid-gestation, Notch pathway signalling elicited expression of NFIA, which bound to the promoters of astrocytic genes such as that encoding GFAP, culminating in demethylation and subsequent activation of these glial genes. Our findings are readily accommodated within the conceptual framework provided by these studies, with the impairment of glial maturation at the cortical midline being a direct consequence of radial progenitors failing to differentiate in the absence of $N f i b$.

Our data indicate that $N f i b$ may also contribute to callosal formation via the cell-autonomous regulation of Npn1 within neurons of the cingulate cortex. Npn1, a cognate ligand for secreted class III semaphorins, has recently been shown to contribute to the formation of the CC $[8,11,43]$. The finding that Npn1 expression is significantly downregulated in the cortex of $N f i b$ mutants implies that the role of $N f i$ genes is not solely confined to gliogenesis, a result that is supported by the broad expression pattern of this gene family within neurons and glia of the developing telencephalon $[21,23]$. Indeed, recent reports have highlighted significant roles for $N f i$ family members in neuronal development. For instance, Nfib has been shown to play a central role in precerebellar mossy fibre neuron generation within the pons [26], while Nfia controls axon outgrowth, dendritogenesis and migration of cerebellar 

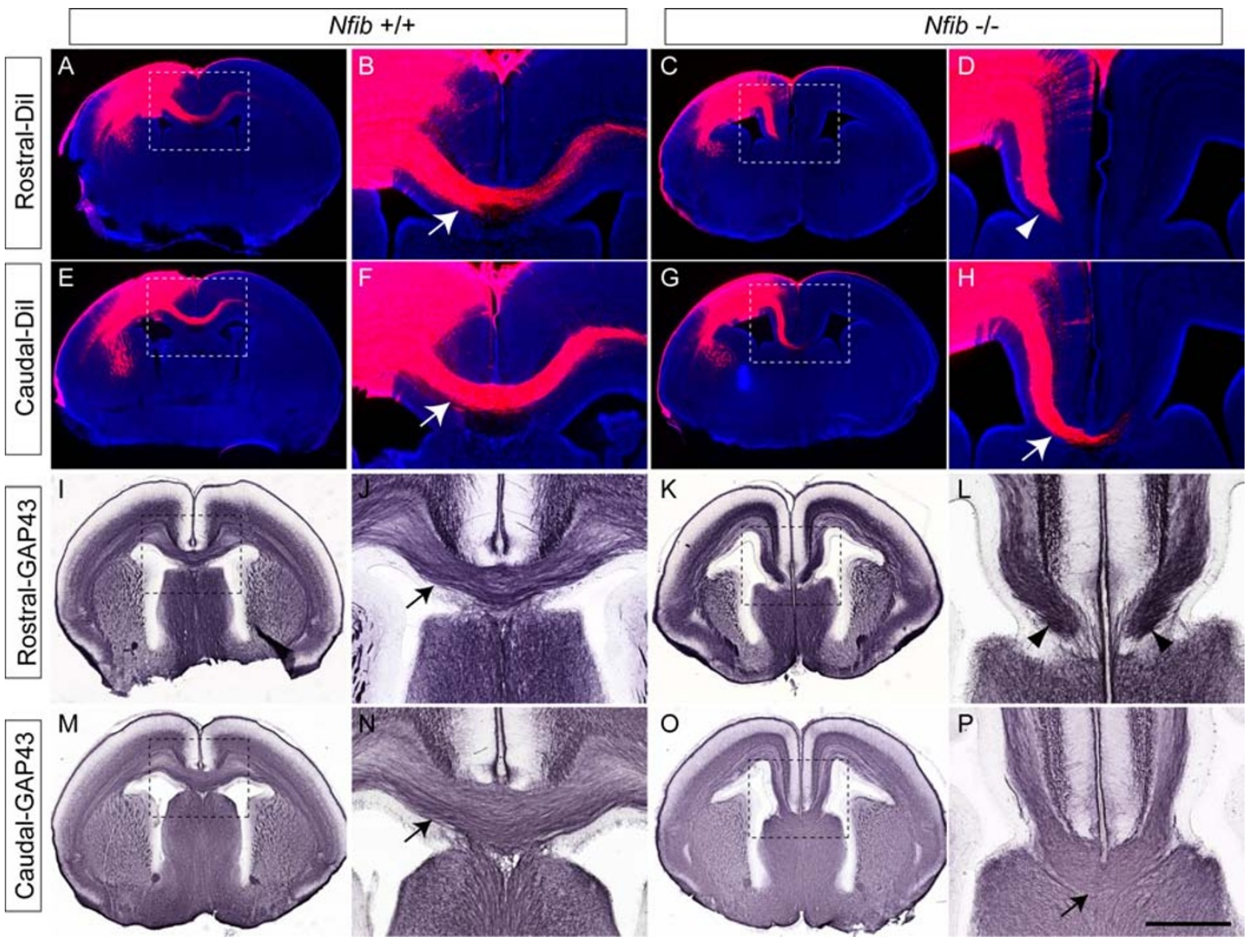

Figure 8

Nfib-deficient mice exhibit callosal dysgenesis. (A-H) Carbocyanine tract tracing in wildtype (A, B, E, F) and Nfib mutant $(C, D, G, H)$ brains at El8. Dil was injected into the neocortex of wildtype and knockout brains, thereby labelling all neocortical projections, including the $C C$. In the wildtype at rostral $(A, B)$ and caudal $(E, F)$ levels, callosal axons were seen projecting across the midline (arrows in (B, F)). In the knockout at rostral levels, no axons were observed crossing the midline (arrowhead in (D)). However, at more caudal levels, a small number of axons were seen crossing into the contralateral cortex (arrow in (H)). (I-P) Immunohistochemistry against the axonal marker GAP43 in wildtype (I, J, M, N) and Nfib mutant (K, L, O, P) brains at EI8. The CC was clearly observed in the wildtype at rostral and caudal levels (arrows in (J, N)). In the mutant at rostral levels, no GAP43-positive axons were seen crossing the midline. Instead, axons stopped adjacent to the midline (arrowheads in (L)). More caudally, however, a small CC was evident in the mutant (arrow in (P)). Panels (B, D, F, H, J, L, N, P) are higher magnifications of the boxed regions in (A, C, E, G, I, K, M, O), respectively. Scale bars: $500 \mu \mathrm{m}(A, C, E, G, I, K, M, O)$; $200 \mu \mathrm{m}(\mathrm{B}, \mathrm{D}, \mathrm{F}, \mathrm{H}, \mathrm{J}, \mathrm{L}, \mathrm{N}, \mathrm{P})$.

granule neurons via regulation of $\mathrm{N}$-cadherin and ephrin B1

[44].

Our finding that a rudimentary CC forms caudally in Nfibdeficient mice appears inconsistent with the initial characterisation of this knockout line, which reported agenesis of the CC [22]. This discrepancy could lie in the age of the embryos investigated, given Steele-Perkins and colleagues conducted their analysis at E17, one day prior to when the present analysis was conducted. Furthermore, the previous study analysed the $N f i b$ allele on a mixed genetic background (129S6/C57Bl/6J). The 129 S6 strain exhibits sporadic occurrence of callosal agenesis [45,46], which may have contributed to the complete absence of the CC observed [22]. The delayed development of the $\mathrm{CC}$ we described in this study is of considerable interest, as it raises the possibility that further development of this tract may occur postnatally. Unfortunately, on the genetic background on which this strain is maintained $(\mathrm{C} 57 \mathrm{Bl} /$ 6J), Nfib knockout mice die at birth due to defective lung maturation [22,47]. Generation of a conditional Nfib allele would be an ideal way to ablate Nfib in a cortex-specific manner, thereby enabling further investigation of CC formation postnatally in the absence of this transcription 

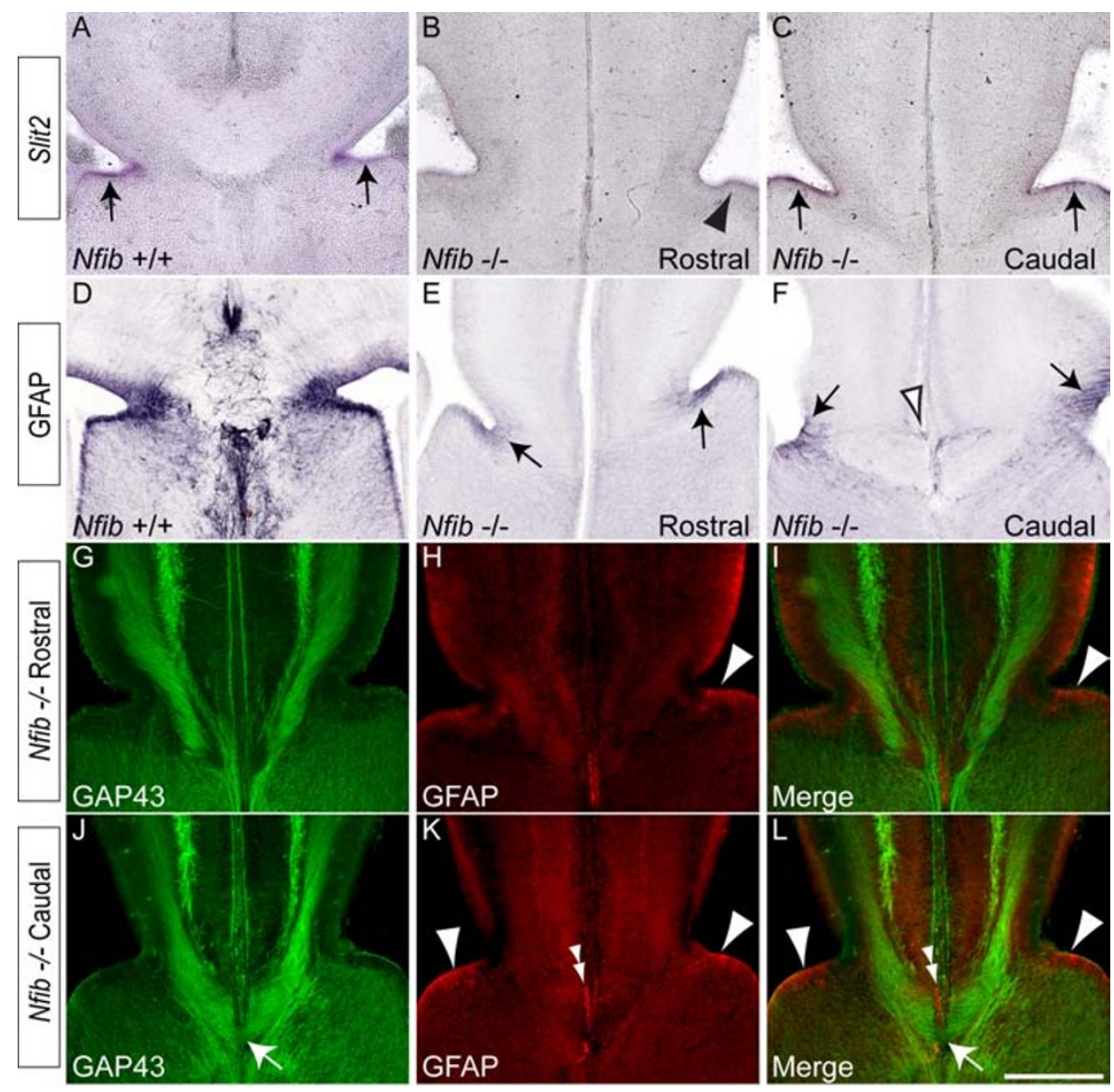

Figure 9

Slit2 expression at the cortical midline. (A) In the wildtype at El 8, expression of the axon guidance cue Slit2 was observed within the glial wedge region (arrows in (A)). (B) In the Nfib null mutant at rostral levels, expression of Slit2 was diminished (arrowhead). (C) At more caudal levels in the mutant, expression of Slit2 in the glial wedge region was more noticeable (arrows). (D) Expression of GFAP in the wildtype at EI8. (E) In Nfib knockout sections at rostral levels, GFAP was observed in the glial wedge (arrows). (F) Further caudally, GFAP was observed in both the glial wedge (arrows) and indusium griseum glia (open arrowhead). (G-L) Co-immunofluorescent labelling of Nfib knockout sections at rostral (G-I) and caudal (J$\mathrm{L}$ ) levels with the axonal marker GAP43 (green) and the astrocytic marker GFAP (red). At rostral levels, no callosal axons could be seen crossing the midline, and few GFAP-positive glia were observed within the glial wedge (arrowheads in (H, I)). At caudal levels, however, more GFAP-positive glia were detected within the glial wedge (arrowheads in (K, L)) and GFAP-positive glia were also seen within the indusium griseum (double arrowheads in $(\mathrm{K}, \mathrm{L})$ ). Callosal axons are also seen crossing the midline at this level (arrows in (J, L)). Scale bar: $200 \mu \mathrm{m}$.

factor. Furthermore, the functional sequelae arising from delayed callosal malformation in these mice could then be investigated using behavioural analyses.

While a hypomorphic CC does form caudally at E18 in the absence of $N f i b$, how this is regulated remains unclear. One possibility is that the caudal CC axons in the Nfib mutant could utilise axons of the hippocampal commissure as a substrate to cross the cortical midline [48]. Another possible determinant of CC formation in the mutant is the delayed development of midline glia within both the glial wedge and indusium griseum. Although the identities of the genes regulating the delayed glial devel- opment in the E18 mutant are unknown, other members of the Nfi gene family are excellent candidates. Nfia and $N f i x$ are both expressed within the glial wedge and indusium griseum at late gestation [23], and furthermore, Nfia and Nfib are expressed in the same cells within the glial wedge at E18 (data not shown). Thus, although differentiation of radial progenitors is delayed in the absence of $N f i b$, compensation by other $N f i$ family members may provide a mechanism for mature glia to eventually form at the cortical midline, thereby enabling development of the CC. Finally, our finding that the anterior commissure and the hippocampal commissure were also disrupted in the $\mathrm{Nfib}-$ - mice could indicate that similar non-cell-autono- 

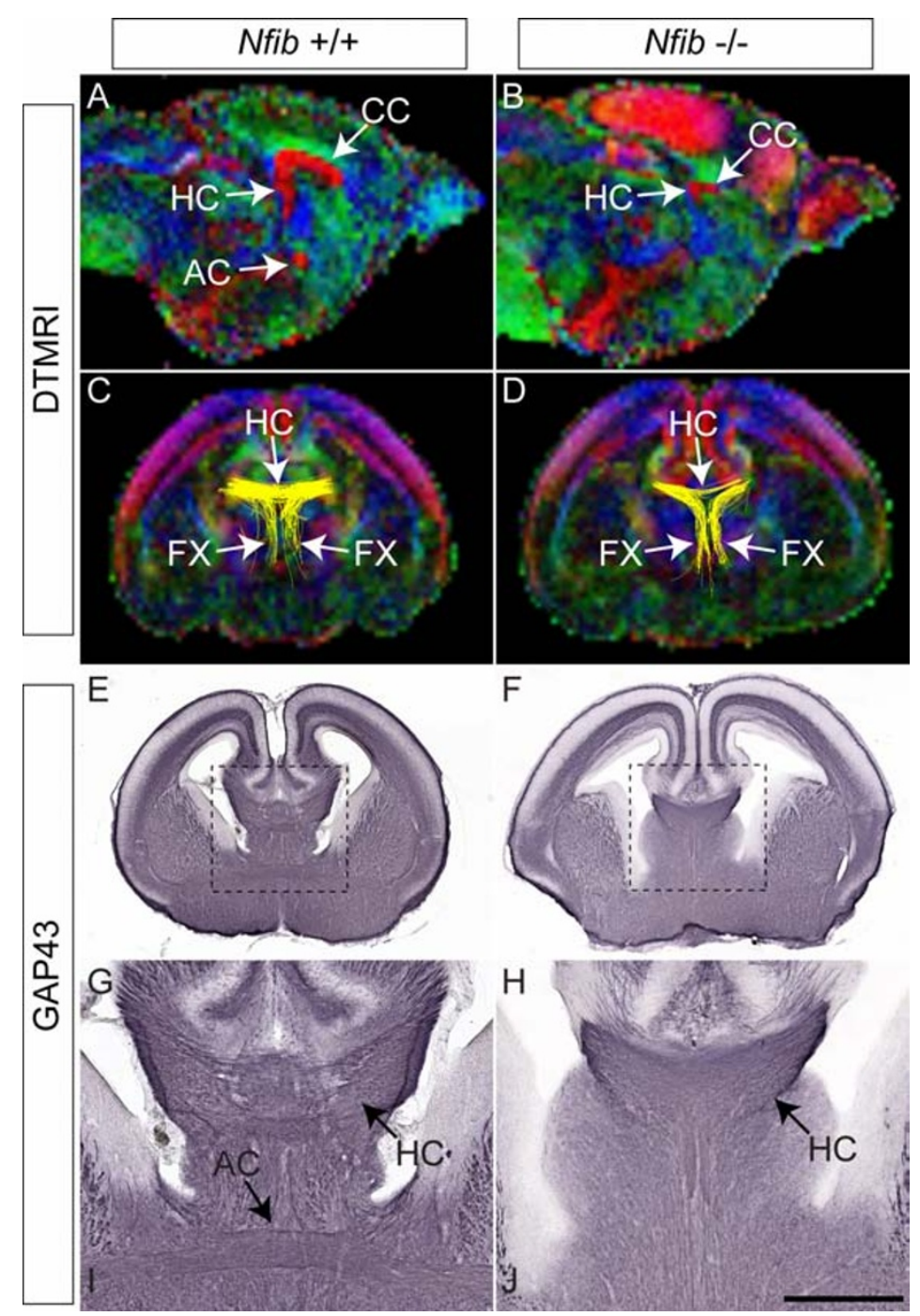

\section{Figure 10}

Hippocampal commissure formation in Nfib null mutants. (A-D) Colour-coded anisotropy maps of EI 8 wildtype (A, C) and Nfib-deficient (B, D) brains. The colour code indicates the direction of axon fibre tracts (blue, dorso-ventrally projecting tracts; red, medio-laterally projecting tracts; green, rostro-caudally projecting tracts). Sections in (A, B) are mid-sagittal views. In the wildtype $(A)$, the three major forebrain commissures were evident; the corpus callosum (CC), the hippocampal commissure $(\mathrm{HC})$ and the anterior commissure $(\mathrm{AC})$. In the Nfib mutant, the anterior commissure was absent, but the corpus callosum and the hippocampal commissure were evident, although much reduced in size. (C, D) Coronal views of the brains scanned in (A, B), in which tractography (yellow lines) was performed on the hippocampal fimbria. The tracts to the hippocampal commissure and the fornix (FX) could be seen at this rostro-caudal position. In the Nfib-deficient brain (D), the size of the hippocampal commissure was reduced in comparison to that of the wildtype control (C). (E-H) The brains represented in (A, B) were cut coronally and axon tracts were revealed via expression of the axonal marker GAP43. In the wildtype (E, G), the hippocampal commissure and anterior commissure were seen crossing the midline. In the Nfib mutant ( $F, H)$, a reduced hippocampal commissure was revealed by GAP43 immunohistochemistry, and the anterior commissure was absent. Panels (G, H) are higher magnifications of the boxed regions in (E, F), respectively. Scale bars: $800 \mu \mathrm{m}(\mathrm{A}, \mathrm{B}) ; 500 \mu \mathrm{m}(\mathrm{C}-\mathrm{F}) ; 200 \mu \mathrm{m}(\mathrm{G}, \mathrm{H})$. 
mous mechanisms, such as the development of midline glial and neuronal sling populations, may underlie the formation of all telencephalic commissures. In conclusion, our data provide a comprehensive insight into the phenotypic abnormalities underlying callosal malformation in Nfib-deficient mice, and demonstrate that multiple factors contribute to these defects during embryogenesis.

\section{Materials and methods Animals}

Litters of wildtype C57Bl/6J and Nfib-deficient mice, bred at The University of Queensland with approval from the institutional Animal Ethics Committee, were used in this study. The N $\mathrm{fib}^{-/}$allele [22] was backcrossed for more than ten generations onto the $\mathrm{C} 57 \mathrm{Bl} / 6 \mathrm{~J}$ background. $\mathrm{Nfib}{ }^{+/-}$mice were bred to obtain wildtype, $\mathrm{Nfib}{ }^{+/}$- and $\mathrm{Nfib}^{-}$ 1-progeny. No midline defects were detected in wildtype or heterozygote animals. Timed-pregnant females were obtained by placing male and female mice together overnight. The following day was designated as E0 if the female had a vaginal plug. Embryos were genotyped by PCR as previously described [22].

\section{Fixation}

On the required gestational day, embryos were drop-fixed in 4\% paraformaldehyde (PFA; E14 and below) or transcardially perfused with $0.9 \%$ phosphate buffered saline, followed by 4\% PFA (E15 to E18). They were then postfixed in $4 \%$ PFA at $4{ }^{\circ} \mathrm{C}$ until sectioning.

\section{Haematoxylin staining}

Brains of E18 wildtype $\mathrm{C} 57 \mathrm{Bl} / 6 \mathrm{~J}$ or $\mathrm{Nfib} \%$ embryos were dissected from the skull, blocked in 3\% noble agar (Difco, Sparks, MD, USA), and then sectioned coronally at $45 \mu \mathrm{m}$ on a vibratome (Leica, Nussloch, Germany). Sections were then mounted and stained with Mayer's haematoxylin using standard protocols.

\section{Immunohistochemistry on floating sections}

Brains were sectioned as described above, then processed free-floating for immunohistochemistry using the chromogen 3,3' diaminobenzidine as described previously [49]. Primary antibodies used for immunohistochemistry were anti-GAP43 (mouse monoclonal, 1/100,000; Chemicon, Bedford, MA, USA), anti-GFAP (rabbit polyclonal, 1/50,000; DAKO, Glostrup, Denmark), anticleaved caspase 3 (rabbit polyclonal, 1/1,000; Cell Signaling Technology, Danvers, MA, USA), anti-GLAST (rabbit polyclonal, 1/50,000; a gift from Niels Danbolt, University of Oslo), anti-nestin (mouse monoclonal, 1/1,500; Developmental Studies Hybridoma Bank), anti-tenascin C (rabbit polyclonal, 1/2,000; Chemicon), anti-Tbr1 (rabbit polyclonal, 1/100,000; a gift from Robert Hevner, University of Washington), anti-NFIA (rabbit polyclonal, 1/ 30,000; Active Motif, Carlsbad, CA, USA), anti-Emx1 (rab- bit polyclonal, 1/30,000; a gift from Giorgio Corte, The University of Genova Medical School), anti-Npn1 (rabbit polyclonal, 1/75,000; a gift from David Ginty, Johns Hopkins University) and anti-DCC (rabbit polyclonal, 1/ 30,000; a gift from Helen Cooper, Queensland Brain Institute). Secondary antibodies used were biotinylated goat-anti-rabbit IgG (1/1,000; Vector Laboratories, Burlingame, CA, USA) and biotinylated donkey-anti-mouse IgG $(1 / 1,000$; Jackson ImmunoResearch, West Grove, PA, USA). To perform immunofluorescent labelling, sections were incubated overnight with the primary antibody at $4{ }^{\circ} \mathrm{C}$. They were then washed and incubated in secondary antibody, before being washed again and mounted. The primary antibodies used for immunofluorescent labelling were anti-phosphohistone $\mathrm{H3}$ (rabbit polyclonal, 1/ 1,000; Millipore, Billerica, MA, USA), anti $\beta$-galactosidase (1/1,000; Promega, Madison, WI, USA), anti-GAP43 (1/ $5,000)$, anti-DCC $(1 / 1,000)$, anti-GFAP $(1 / 2,000)$, antiSatb2 (1/1,000; Abcam, Cambridge, UK) and anti-NFIB $(1 / 1,000)$. The secondary antibodies used were goat-antirabbit IgG AlexaFluor488 and goat-anti-mouse IgG AlexaFluor594 (both 1/1,000; Invitrogen, Carlsbad, CA).

\section{Immunohistochemistry on paraffin sections}

E18 wildtype brains were perfused as above and embedded in paraffin wax. Brains were sectioned at a thickness of $6 \mu \mathrm{m}$. Antigen retrieval was performed using a $10 \mathrm{mM}$, pH 6 sodium citrate solution, and immunohistochemistry was performed as described above using 3,3' diaminobenzidine as the chromogen. The primary antibody used for immunohistochemistry was anti-NFIB $(1 / 1,000$, Active Motif), and a biotinylated goat-anti-rabbit IgG secondary antibody (Vector Laboratories) was used at 1/1,000.

\section{Image acquisition and analysis}

Following immunohistochemistry, sections were imaged using an upright microscope (Zeiss Z1, Zeiss, Goettingen, Germany) attached to a digital camera (Zeiss AxioCam HRc). AxioVision software (Zeiss) was used to capture images. When comparing wildtype to knockout tissue, sections from matching positions along the rostro-caudal axis were selected.

\section{Quantification of proliferation}

To quantify proliferation at the developing cortical midline, sections from E13, E14 and E15 wildtype C57Bl/6J or $\mathrm{Nfib} /$ - embryos were labelled with an anti-phosphohistone $\mathrm{H} 3$ antibody as described above. Sections were imaged using an upright fluorescence microscope (Zeiss Z1) attached to a digital camera (Zeiss AxioCam HRc). Eight to ten optical sections encompassing the entire 45$\mu \mathrm{m}$ section were captured with an ApoTome (Zeiss). To calculate the total number of phosphohistone H3-positive cells per unit area at the cortical midline, a $300 \mu \mathrm{m}^{2}$ boxed region, encompassing the presumptive glial wedge 
area, was generated using AxioVision software (Zeiss). The number of immunolabelled cells in focus in each optical section of this region was counted and pooled ( $n=3$ for both wildtype and knockout at all ages).

\section{Statistical analysis}

For all experiments described in this study, sections from three different brains of each genotype were analysed. Statistical analyses were performed using a two-tailed unpaired $t$-test. Error bars represent standard error of the mean.

\section{Carbocyanine tract tracing}

E18 wildtype and $\mathrm{Nfib} /$ - brains were fixed in 4\% PFA as described above. A small injection of DiI (in a 10\% solution of dimethylformamide; Invitrogen) was then made into the neocortex using a pulled glass pipette attached to a picospritzer. Brains were stored in the dark at $37^{\circ} \mathrm{C}$ in $4 \%$ PFA for at least 4 weeks to allow dye transport. They were then sectioned coronally at $45 \mu \mathrm{m}$ using a vibratome, and imaged using an upright fluorescence microscope (Zeiss Z1). Nuclei were counterstained with 4',6-diamidino-2-phenylindole (DAPI; blue). Three brains were analysed for each genotype.

\section{Retrograde labelling under ultrasound guidance}

Pregnant mice were anaesthetised with isofluorane (2\%) for the duration of the microinjection procedures. The uterine horn was exposed through an incision in the abdominal midline for the purpose of ultrasound- imaging and guided microinjections (Vevo770, VisualSonics, Toronto, Canada). Retrograde labelling of callosal axons with True Blue chloride (Invitrogen) was performed as described previously, with modifications appropriate for ultrasound-guided microinjection in utero. Embryos were visualised under a $40 \mathrm{MHz}$ transducer probe (RMV711) and a small volume of the tracer (approximately $250 \mathrm{~nL}$ of a $1 \mu \mathrm{g} / \mu \mathrm{L}$ solution) was injected into the cortex of wildtype E17 embryos in utero through the uterine wall with the aid of a nanojector (Nanoject II, Drummond Scientific, Broomall, PA, USA). Once embryos were injected, the uterine horn was returned to the abdominal cavity, and the incision was sutured. Then, 24 hours later (E18) the embryos were perfused transcardially as described above and processed for NFIB immunohistochemistry. Fluorescence images were obtained with an upright microscope (Zeiss Z1) as described above.

\section{In situ hybridisation}

In situ hybridisation was performed as described previously [50], with minor modifications. An antisense riboprobe specific to Slit2 was hybridised to coronal brain sections at $65^{\circ} \mathrm{C}$ overnight. The colour reaction solution was BM Purple (Roche, Mannheim, Germany).

\section{Reverse transcription and quantitative real-time PCR}

The reverse transcription was performed using Superscript III (Invitrogen). Briefly, $0.5 \mu \mathrm{g}$ total RNA was reverse transcribed with random hexamers. qPCR reactions were carried out in a Rotor-Gene 3000 (Corbett Life Science, Sydney, Australia) using the SYBR Green PCR Master Mix (Invitrogen). All the samples were diluted 1/100 with water and $5 \mu \mathrm{L}$ of these dilutions were used for each SYBR Green PCR reaction containing $10 \mu \mathrm{L}$ SYBR Green PCR Master Mix, $10 \mu \mathrm{M}$ of each primer, and deionised water. The reactions were incubated for 10 minutes at $95^{\circ} \mathrm{C}$ followed by 40 cycles with 15 seconds denaturation at $95^{\circ} \mathrm{C}$, 20 seconds annealing at $60^{\circ} \mathrm{C}$, and 30 seconds extension at $72^{\circ} \mathrm{C}$. Primer sequences are available on request.

\section{Quantitative real-time PCR data expression and analysis} After completion of the PCR amplification, the data were analysed with the Rotor-Gene software (Corbett Life Science) and Microsoft Excel. In order to quantify the mRNA expression levels, the housekeeping gene HPRT was used as a relative standard. All the samples were tested in triplicate. By means of this strategy, we achieved a relative PCR kinetic of the standard and the sample. For all qPCR analyses, RNA from three independent replicates for both wildtype and Nfib mutants were interrogated. Statistical analyses were performed using a two-tailed unpaired $t$ test. Error bars represent the standard error of the mean.

\section{Diffusion-weighted magnetic resonance imaging and tractography}

Following perfusion fixation and phosphate-buffered saline washing, diffusion-weighted images were acquired with the samples immersed in Fomblin Y-LVAC fluid (Solvay Solexis, Italy), using a 16.4 Tesla Bruker scanner and a $10 \mathrm{~mm}$ quadrature birdcage coil. A three-dimensional diffusion-weighted spin-echo sequence was acquired using a repetition time of $400 \mathrm{~ms}$, an echo time of $22.8 \mathrm{~ms}$ and an imaging resolution of $0.08 \times 0.08 \times$ $0.08 \mathrm{~mm}$ with a signal average of 1 . Each dataset was composed of two $B_{\mathrm{o}}$ and thirty direction diffusion-weighted images ( $b$ value of $5,000 \mathrm{~s} / \mathrm{mm}^{2}, \delta / \Delta=2.5 / 14 \mathrm{~ms}$ ). Reconstruction and tractography were performed with Diffusion Toolkit [51] according to high angular resolution diffusion (HARDI) and Q-ball models [52]. Tractography limits were set at fractional anisotropy values greater than 0.1 and a turning angle $\leq 45^{\circ}$. Hippocampal commissure tractography was performed using hand-drawn regionsof-interest on colour-coded fractional anisotropy maps in TrackVis [53].

\section{Abbreviations}

CC: corpus callosum; DCC: Deleted in colorectal cancer; DTMRI: diffusion tensor magnetic resonance imaging; E: embryonic day; GFAP: glial fibrillary acidic protein; GLAST: astrocyte-specific glutamate transporter; Npn1: 
neuropilin 1; PFA: paraformaldehyde; qPCR: quantitative real-time PCR.

\section{Competing interests}

The authors declare that they have no competing interests.

\section{Authors' contributions}

MP and LJR conceived the study, evaluated the findings, prepared the figures and the manuscript. RMG generated the Nfib mutant strain. MP, RXM, CL, EL, GB, SM, NS and NDK carried out all the experimental procedures.

\section{Additional material}

\section{Additional file 1}

Figure S1 - Co-expression of NFIB and $\beta$-galactosidase in Nfib heterozygous mice. (A-I) Confocal image of an E18 Nfib heterozygote brain demonstrating expression of ( $\beta$-galactosidase $(\beta$-gal, $A, D, G)$ and NFIB $(B, E, H)$ at the cortical midline. (A-C) Low power image of the cortical midline, demonstrating extensive co-expression of $\beta$-gal and NFIB (C). $(D-F)$ Higher magnification view of the glial wedge (GW), demonstrating that the majority of cells in this region co-express NFIB and $\beta$-gal, in particular those cells located at the ventricular surface (arrowhead in F). (G-I) Higher magnification view of the indusium griseum glia (IGG), showing that these cells express both NFIB and $\beta$-gal (arrows in I). Scale bar: A-C $200 \mu m ; D-I 100 \mu m$.

Click here for file

[http://www.biomedcentral.com/content/supplementary/17498104-4-43-S1.TIFF]

\section{Additional file 2}

Figure S2 - Reduction of tenascin C expression in the absence of $\mathrm{Nfib}$ Coronal sections of wildtype $(A, C)$ and Nfib-deficient $(B, D)$ brains. Expression of the glial marker tenascin $C$ was reduced at the cortical midline of mice lacking Nfib at both E15 (B) and E16 (D). Scale bar: A, B $280 \mu \mathrm{m} ; \mathrm{C}, \mathrm{D} 250 \mu \mathrm{m}$.

Click here for file

[http://www.biomedcentral.com/content/supplementary/1749-

8104-4-43-S2.TIFF]

\section{Additional file 3}

Figure S3 - Expression of NFIB and Satb2 in the neocortex. Confocal image of an E18 wildtype brain. (A) DAPI nuclear staining; the boxed region indicates the position of panels B-D. Satb2, a marker for callosally projecting axons, was expressed predominantly in upper layers of the cortical plate (B). NFIB expression was highest in the deeper cortical layers, but was also seen in layers II/III (C). Most cells within the cortical plate did not co-express NFIB and Satb2 (D), although some overlap was evident in layers II/III. Scale bar: A $500 \mu \mathrm{m} ; B-D 100 \mu \mathrm{m}$.

Click here for file

[http://www.biomedcentral.com/content/supplementary/17498104-4-43-S3.TIFF]

\section{Acknowledgements}

We thank John Baisden, Oressia Zalucki, Jane Ellis and the UQBR Animal Facility for technical assistance, Marc Tessier-Lavigne (Genentech) for the Slit2 riboprobe and Robert Hevner (University of Washington), Helen Cooper (Queensland Brain Institute), Giorgio Corte (University of Genova
Medical School) and Niels Danbolt (University of Oslo) for reagents. The 16.4T facility is part of the Queensland NMR network, funded by the Queensland Government Smart State initiative. This work was funded by a National Health and Medical Research Council project grant (LJR) and a Clive and Vera Ramaciotti grant (MP). The following authors were supported by National Health and Medical Research Council fellowships: LJR (Senior Research Fellowship); MP (Howard Florey Centenary Fellowship and Biomedical Career Development Award); RXM (CJ Martin Fellowship). SM is supported by a University of Queensland F.G Meade PhD Scholarship. NDK is grateful for the support of Lembaga Eijkman, Jakarta.

\section{References}

I. Lindwall C, Fothergill T, Richards LJ: Commissure formation in the mammalian forebrain. Curr Opin Neurobiol 2007, 17:3-14.

2. Yorke CH Jr, Caviness VS Jr: Interhemispheric neocortical connections of the corpus callosum in the normal mouse: a study based on anterograde and retrograde methods. J Comp Neurol 1975, 164:233-245.

3. Paul LK, Brown WS, Adolphs R, Tyszka JM, Richards LJ, Mukherjee P, Sherr EH: Agenesis of the corpus callosum: genetic, developmental and functional aspects of connectivity. Nat Rev Neurosci 2007, 8:287-299.

4. LaMantia AS, Rakic P: Axon overproduction and elimination in the corpus callosum of the developing rhesus monkey. J Neurosci 1990, 10:2156-2175.

5. Alcamo EA, Chirivella L, Dautzenberg M, Dobreva G, Farinas I, Grosschedl R, McConnell SK: Satb2 regulates callosal projection neuron identity in the developing cerebral cortex. Neuron 2008, 57:364-377.

6. Britanova O, de Juan Romero C, Cheung A, Kwan KY, Schwark M, Gyorgy A, Vogel T, Akopov S, Mitkovski M, Agoston D, Sestan N, Molnar Z, Tarabykin V: Satb2 is a postmitotic determinant for upper-layer neuron specification in the neocortex. Neuron 2008, 57:378-392.

7. Serafini T, Colamarino SA, Leonardo ED, Wang $H$, Beddington R, Skarnes WC, Tessier-Lavigne M: Netrin-I is required for commissural axon guidance in the developing vertebrate nervous system. Cell 1996, 87:100I-I0I4.

8. Piper M, Plachez C, Zalucki O, Fothergill T, Goudreau G, Erzurumlu $\mathrm{R}, \mathrm{Gu} \mathrm{C}$, Richards LJ: Neuropilin I-Sema signaling regulates crossing of cingulate pioneering axons during development of the corpus callosum. Cereb Cortex 2009, I 9(SuppI I):il I-2I.

9. Bagri A, Marin O, Plump AS, Mak J, Pleasure SJ, Rubenstein JL, TessierLavigne M: Slit proteins prevent midline crossing and determine the dorsoventral position of major axonal pathways in the mammalian forebrain. Neuron 2002, 33:233-248.

10. Fazeli A, Dickinson SL, Hermiston ML, Tighe RV, Steen RG, Small CG, Stoeckli ET, Keino-Masu K, Masu M, Rayburn H, Simons J, Bronson RT, Gordon JI, Tessier-Lavigne M, Weinberg RA: Phenotype of mice lacking functional Deleted in colorectal cancer (Dcc) gene. Nature 1997, 386:796-804.

II. Gu C, Rodriguez ER, Reimert DV, Shu T, Fritzsch B, Richards LJ, Kolodkin AL, Ginty DD: Neuropilin-I conveys semaphorin and VEGF signaling during neural and cardiovascular development. Dev Cell 2003, 5:45-57.

12. Andrews W, Liapi A, Plachez C, Camurri L, Zhang J, Mori S, Murakami F, Parnavelas JG, Sundaresan V, Richards LJ: Robol regulates the development of major axon tracts and interneuron migration in the forebrain. Development 2006, 133:2243-2252.

13. Keeble TR, Halford MM, Seaman C, Kee N, Macheda M, Anderson RB, Stacker SA, Cooper HM: The Wnt receptor Ryk is required for Wnt5a-mediated axon guidance on the contralateral side of the corpus callosum. J Neurosci 2006, 26:5840-5848.

14. Wang CL, Zhang L, Zhou Y, Zhou J, Yang XJ, Duan SM, Xiong ZQ, Ding YQ: Activity-dependent development of callosal projections in the somatosensory cortex. J Neurosci 2007, 27: I I334- II342.

15. Piper M, Dawson AL, Lindwall C, Barry G, Plachez C, Richards LJ: Emx and $\mathrm{Nfi}$ genes regulate cortical development and axon guidance in the telencephalon. Novartis Found Symp 2007, 288:230-242. discussion 242-235, 276-28।

16. Shu T, Richards LJ: Cortical axon guidance by the glial wedge during the development of the corpus callosum. J Neurosci 200I, 2I:2749-2758. 
17. Smith KM, Ohkubo Y, Maragnoli ME, Rasin MR, Schwartz ML, Sestan $\mathrm{N}$, Vaccarino FM: Midline radial glia translocation and corpus callosum formation require FGF signaling. Nat Neurosci 2006, 9:787-797.

18. Shu T, Puche AC, Richards LJ: Development of midline glial populations at the corticoseptal boundary. I Neurobiol 2003, 57:8I-94.

19. Deneen B, Ho R, Lukaszewicz A, Hochstim CJ, Gronostajski RM, Anderson DJ: The transcription factor NFIA controls the onset of gliogenesis in the developing spinal cord. Neuron 2006, 52:953-968.

20. Shu T, Butz KG, Plachez C, Gronostajski RM, Richards LJ: Abnormal development of forebrain midline glia and commissural projections in Nfia knock-out mice. J Neurosci 2003, 23:203-2I2.

21. Barry G, Piper M, Lindwall C, Moldrich R, Mason S, Little E, Sarkar A, Tole S, Gronostajski RM, Richards LJ: Specific glial populations regulate hippocampal morphogenesis. I Neurosci 2008, 28: I2328- 12340 .

22. Steele-Perkins G, Plachez C, Butz KG, Yang G, Bachurski CJ, Kinsman SL, Litwack ED, Richards LJ, Gronostajski RM: The transcription factor gene $\mathbf{N}$ fib is essential for both lung maturation and brain development. Mol Cell Biol 2005, 25:685-698.

23. Plachez C, Lindwall C, Sunn N, Piper M, Moldrich RX, Campbell CE, Osinski JM, Gronostajski RM, Richards LJ: Nuclear factor I gene expression in the developing forebrain. J Comp Neurol 2008, 508:385-40I.

24. Shu T, Li Y, Keller A, Richards LJ: The glial sling is a migratory population of developing neurons. Development 2003, I 30:2929-2937.

25. Silver J, Lorenz SE, Wahlsten D, Coughlin J: Axonal guidance during development of the great cerebral commissures: descriptive and experimental studies, in vivo, on the role of preformed glial pathways. J Comp Neurol 1982, 2 10:10-29.

26. Kumbasar A, Plachez C, Gronostajski RM, Richards LJ, Litwack ED: Absence of the transcription factor Nfib delays the formation of the basilar pontine and other mossy fiber nuclei. J Comp Neurol 2009, 5 I 3:98- I I 2.

27. Wyss JM, Sripanidkulchai K: The indusium griseum and anterior hippocampal continuation in the rat. J Comp Neurol 1983, 219:251-272.

28. Dahlstrand J, Lardelli M, Lendahl U: Nestin mRNA expression correlates with the central nervous system progenitor cell state in many, but not all, regions of developing central nervous system. Brain Res Dev Brain Res 1995, 84:109-129.

29. Gotz M, Barde YA: Radial glial cells defined and major intermediates between embryonic stem cells and CNS neurons. Neuron 2005, 46:369-372.

30. Hartfuss E, Galli R, Heins N, Gotz M: Characterization of CNS precursor subtypes and radial glia. Dev Biol 200I, 229:15-30.

31. Gotz M, Stoykova A, Gruss P: Pax6 controls radial glia differentiation in the cerebral cortex. Neuron 1998, 21:1031-1044.

32. Koester SE, O'Leary DD: Axons of early generated neurons in cingulate cortex pioneer the corpus callosum. J Neurosci I994, | 4:6608-6620.

33. Rash BG, Richards LJ: A role for cingulate pioneering axons in the development of the corpus callosum. J Comp Neurol 200I, 434: I47-I57.

34. Shu T, Valentino KM, Seaman C, Cooper HM, Richards LJ: Expression of the netrin-I receptor, deleted in colorectal cancer (DCC), is largely confined to projecting neurons in the developing forebrain. J Comp Neurol 2000, 4 I 6:201-2I 2.

35. Shu T, Shen WB, Richards LJ: Development of the perforating pathway: an ipsilaterally projecting pathway between the medial septum/diagonal band of Broca and the cingulate cortex that intersects the corpus callosum. J Comp Neurol 200I, 436:4II-422.

36. Ren T, Anderson A, Shen WB, Huang H, Plachez C, Zhang J, Mori S, Kinsman SL, Richards LJ: Imaging, anatomical, and molecular analysis of callosal formation in the developing human fetal brain. Anat Rec A Discov Mol Cell Evol Biol 2006, 288: I9l-204.

37. Mason S, Piper M, Gronostajski RM, Richards LJ: Nuclear factor one transcription factors in CNS development. Mol Neurobiol 2009, 39:10-23.

38. Cebolla $B$, Vallejo $M$ : Nuclear factor-I regulates glial fibrillary acidic protein gene expression in astrocytes differentiated from cortical precursor cells. J Neurochem 2006, 97:1057-1070.
39. Bisgrove DA, Monckton EA, Packer M, Godbout R: Regulation of brain fatty acid-binding protein expression by differential phosphorylation of nuclear factor I in malignant glioma cell lines. J Biol Chem 2000, 275:30668-30676.

40. Gopalan SM, Wilczynska KM, Konik BS, Bryan L, Kordula T: Nuclear factor-I-X regulates astrocyte-specific expression of the alphal-antichymotrypsin and glial fibrillary acidic protein genes. J Biol Chem 2006, 28 I: |3126-13133.

41. Copertino DW, Edelman GM, Jones FS: Multiple promoter elements differentially regulate the expression of the mouse tenascin gene. Proc Natl Acad Sci USA 1997, 94: I846- I85I.

42. Namihira M, Kohyama J, Semi K, Sanosaka T, Deneen B, Taga T, Nakashima K: Committed neuronal precursors confer astrocytic potential on residual neural precursor cells. Dev Cell 2009, 16:245-255.

43. Hatanaka Y, Matsumoto T, Yanagawa $Y$, Fujisawa H, Murakami F, Masu M: Distinct roles of neuropilin I signaling for radial and tangential extension of callosal axons. J Comp Neurol 2009, 5 1 4:215-225.

44. Wang W, Mullikin-Kilpatrick D, Crandall JE, Gronostajski RM, Litwack ED, Kilpatrick DL: Nuclear factor I coordinates multiple phases of cerebellar granule cell development via regulation of cell adhesion molecules. I Neurosci 2007, 27:6II5-6I27.

45. Wahlsten D: Deficiency of corpus callosum varies with strain and supplier of the mice. Brain Res 1982, 239:329-347.

46. Wahlsten D, Bishop KM, Ozaki HS: Recombinant inbreeding in mice reveals thresholds in embryonic corpus callosum development. Genes Brain Behav 2006, 5:170-I88.

47. Grunder A, Ebel TT, Mallo M, Schwarzkopf G, Shimizu T, Sippel AE, Schrewe H: Nuclear factor I-B (Nfib) deficient mice have severe lung hypoplasia. Mech Dev 2002, I I 2:69-77.

48. Livy DJ, Wahlsten D: Retarded formation of the hippocampal commissure in embryos from mouse strains lacking a corpus callosum. Hippocampus 1997, 7:2-14.

49. Campbell CE, Piper M, Plachez C, Yeh YT, Baizer JS, Osinski JM, Litwack ED, Richards LJ, Gronostajski RM: The transcription factor Nfix is essential for normal brain development. BMC Dev Biol 2008, 8:52.

50. Piper M, Georgas K, Yamada T, Little M: Expression of the vertebrate Slit gene family and their putative receptors, the Robo genes, in the developing murine kidney. Mech Dev 2000, 94:213-217.

5I. Diffusion Toolkit [http://trackvis.org/dtk/]

52. Hess CP, Mukherjee P, Han ET, Xu D, Vigneron DB: Q-ball reconstruction of multimodal fiber orientations using the spherical harmonic basis. Magn Reson Med 2006, 56: I04-I I 7.

53. TrackVis [http://trackvis.org/]

Publish with Biomed Central and every scientist can read your work free of charge

"BioMed Central will be the most significant development for disseminating the results of biomedical research in our lifetime."

Sir Paul Nurse, Cancer Research UK

Your research papers will be:

- available free of charge to the entire biomedical community

- peer reviewed and published immediately upon acceptance

- cited in PubMed and archived on PubMed Central

- yours - you keep the copyright

Submit your manuscript here:

http://www.biomedcentral.com/info/publishing_adv.asp 